\title{
Perception Of Space, Empathy And Cognitive Processes: Design Of A Video Game For The Measurement Of Perspective Taking Skills
}

\author{
http://dx.doi.org/10.3991/ijet.v9i7.3718 \\ Pio Alfredo Di Tore \\ Università degli Studi di Salerno, Salerno, Italy
}

\begin{abstract}
The perspective-taking skills require the ability to manipulate spatial reference systems and are the basis of the empathetic process. Empathy, in its relations with space representation and manipulation of spatial reference systems, is the investigation subject of this work, whose aim is the design of a videogame aimed at the measurement of the player's perspective taking skills. The idea of creating a video game on perspective taking is based on a classic Piagetian task, the three mountains problem, object of recent attention by the Italian scientific community that is involved in research in education. The current stage of the project has produced a video game, now in alpha testing release. The article discusses the software theoretical framework (spatial theory of empathy), describes the choices made in the design stage and comment on first results obtained during the alpha testing.
\end{abstract}

Index Terms - Empathy, Spatial reference frames, Learning, Avatar, Perspective Taking.

\section{INTRODUCTION}

The aim of this article is to provide advance notice of an ongoing research, introducing the theoretical framework underlying the design of a video game aimed at measuring perspective taking skills.

The study aims to offer a perspective on the relationship between space and education, on the assumption, developed by Alain Berthoz, that mental tools developed during evolution in order to solve the problems posed by the advancement in space have been used also for higher cognitive functions: memory and reasoning, relationship with the other and also creativity [1].

Specifically, the goal of the project presented below is the definition of an instrument that allows to investigate the perspectives of the actors of the teaching-learning process.

The instrument being developed is an interactive 3D environment that allows the manipulation of points of view.

The perspective-taking skill, or, literally, the ability to take the perspective of others, requires the ability to manipulate spatial reference systems and is the basis of the empathetic process. Empathy, in its relations with the space representation, spatial reference systems handling and mental rotation ability, is the main object of study of this work. The theoretical framework is based on a welldefined position: Having said that there are as many definitions of "empathy" as many researchers in various do- mains have dealt with the topic [2], here we choose a precise meaning, the spatial theory of empathy, developed by Alain Berthoz.

\section{EMPATHY AND SPATIAL REFERENCE FRAMES}

The spatial position of an object can be represented by the central nervous system with respect to different classes of reference points, which may be related or not to the position of the subject.

A reference frame is a coordinate system through which relative positions of objects in space are encoded [3].

In a nutshell, we can say that there are two types of transformations of space imagery: the allocentric spatial transformations, that involve an object-to-object representation system and encode information about the location of an object or its parts in relation to other objects, and the egocentric spatial transformations that involve a subjectobject representation system.

\section{A. Allocentric (object - object) reference frame}

The information on the position of an object is encoded according to the position of other objects. The position of an object is relative to the position of other objects.

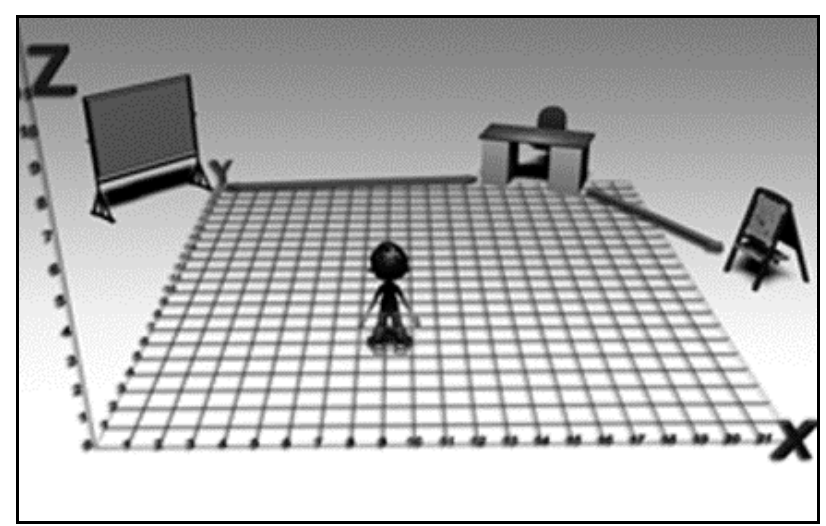

Figure 1. Allocentric (object - object) reference frame

\section{B. Egocentric(subject - object) reference frame}

The information on the position of an object is encoded according to the body axes of the subject. The position of an object is relative to the position of the subject. The image below has been realized using polar coordinates, but it is possible to represent the egocentric system using the Cartesian plane formed by the intersection of the frontal plane and the sagittal plane. 


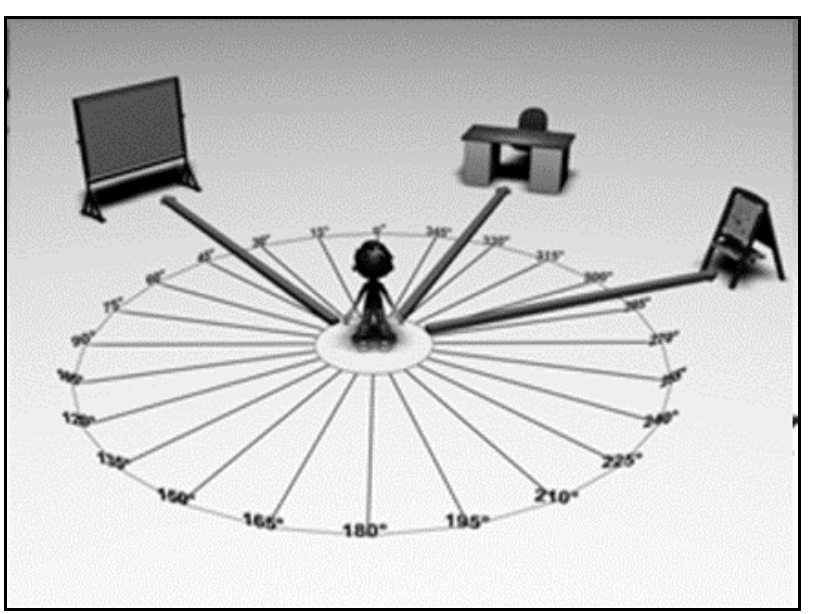

Figure 2. Egocentric (subject - object) reference frame

The two types of representation coexist. Human being switches from one encoding to another, depending on the contingent requirements, giving preference to one or another system according to a set of heterogeneous factors. The gender difference, for example, plays a key role. Even the individual cognitive strategies make use of different representations in a significantly different way. The transition from one encoding to another is mainly related to the evolutionary development of the individual.

According to Piaget, the child is able to imagine different views from seven or eight years.

Piaget makes it immediately clear that the manipulation of point of view is linked to other mechanisms: only at the age of eight years intellectual space will be built, capable of definitively overriding the perceived space and allowing manipulation of viewpoints that is not just spatial but, also combines a variety of mechanisms of representation.

"[...] l'espace intellectuel sera construit, capable de l'emporter définitivement sur l'espace perceptible et de permettre une manipulation des points de vue qui n'est pas simplement spatiale mais qui, en fait, associe aussi toute une série de mécanismes de représentation, et même sémantiques" [4].

Piaget's ideas on child mental development have focused on egocentrism in early childhood, on the basis of experimental studies, such as the famous "three mountains task" [4].

In this test, a child must indicate the point of view of an observer who is in a different location.

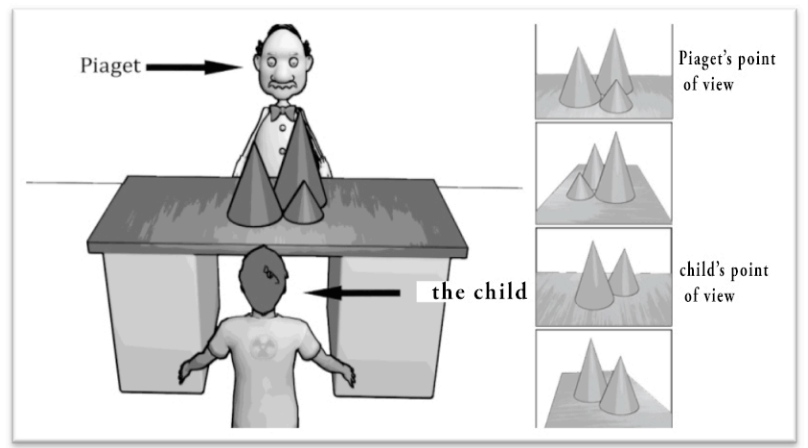

Figure 3. A possible representation of the "problem of the three mountains." In this task, the child is asked to identify which of those proposed, is the point of view of the person on the other side of the table.
By using this paradigm, children up to 7 years does not seem to have the ability to assess a point of view other than their own.

Only when the children reach the stage of concrete operations, between 7 and 12 years, they gain the ability to "decentralization". This allows them to take into account multiple aspects of a task to solve it. According to Piaget, egocentrism, defined as inability to decentralize and take the perspective of another person, is the norm in young children.

Piaget's theory on egocentrism has sparked a lively debate of which Perner provides a comprehensive overview [5]. Rochat has shown that children of 3 years of age are able to discriminate what can reach directly from what instead is reachable by someone else. The conclusion of Rochat is clear: since the age of three years, the children can take the perspective of others, and are capable of spatial decentralization and flexibility in the spatial reference systems depending on the operation to be performed [6].

Even Martin Hughes has criticized the three mountains task. According to Hughes, this task does not make sense for children [7]. In 1975, Helen Borke [8] proposed a modification of Piaget's mountain experiment. Borke found that simplifying the stimulus and response aspects of the mountain task made problem solution easier for young children.

An experiment carried out by Hughes [7] confirmed Borke's findings, showing that children have largely lost their egocentric thinking by four years of age, because they are able to take the view of another.

The point that seems particularly interesting for the purposes of this work is not the disagreement between Piaget and post-piagetian researchers about the age at which a child can take the perspective of others. Beyond the age parameter, all researchers share the same approach to the definition of "allocentric" and "egocentric". The task of the three mountains requires to take the visuospatial perspective of another person. This perspective, albeit about a different subject, it is still an egocentric perspective. The three mountains task, according to Frith and de Vignemont, is always based on an egocentric representation of the object and cannot inform on the ability about taking an allocentric perspective by young children [9].

This seems to be in agreement with the view of the Vogeley and Fink, according to which "the difference between first and third-person perspective is that 3PP (Third Person Camera) necessitates a translocation of the egocentric viewpoint" [10].

The ability to assume an allocentric perspective, however, is not reducible to the mechanical assumption of the position of others in the space. The central node is the possibility to make a "mental rotation, in relation to the environment or to an object in the environment, while maintaining a main perspective environment in question" [11].

Basically, it is to be both yourself and the other. Precisely this is the key feature, for Alain Berthoz, of empathy: empathy is a dynamic process that requires a doubling. It is, in short, to adopt an egocentric point of view, but after an allocentric manipulation, while inhibiting the emotional contagion, which is rather typical of sympathy.

The spatial manipulation, from this point of view, it is one of the cornerstones of the concept of empathy. 


\section{SPATIAL THEORY OF EMPATHY}

The spatial theory of empathy is based on the ability human to act on the management point of view. The work by Berthoz, gained in the studies on Physiologie $d u$ changement de point de vue [12], is a continuation of the phenomenological tradition.

In relation to a modern conception of the philosophical tradition of phenomenology and a primary role of cognitive embodiment, there is a basic difference between sympathy and empathy. While sympathy is akin to an emotional contagion and does not require the subject to adopt the point of view of others, empathy requires a dynamic and complex manipulation of spatial reference systems [13].

By adopting this approach, empathy is a modality that allows us to relate with the other without attributing to ourselves "what the other is experiencing," quite entering the bodies of others to assume their point of view, or to see the world with the eyes of others. German philosophy had already pointed out, at the end of the 19th century, this aspect, using the term "Einfühlung", to "feel (fühlen) into (ein)" $[14,15]$.

In Einfühlung, the prefix ein refers to a space process of mental simulation through which we imagine to be placed in the body of others (spatial aspect). The root fühlen instead refers to a subjective experience of sensory or emotional nature. The same etymological root, therefore, suggests a dynamic interaction between the simultaneous experiences of our own bodies and the bodies of others [13].

In fact, this approach represents a reversal with respect to neuroscientific perspective that "addressed the question of the neural basis of sympathy and emotion via emotional contagion and resonance and do not address the complex dynamic mechanisms of empathy" [13].

In the hypothesis developed at the Collège de France, four processes underlying the empathic relationships were identified:

1. The construction of a coherent perception of our body and its relationship with the environment.

2. The ability to resonate with the emotions and perceptions of others.

3. The ability to change the point of view or perspective and move our body and our brain in the body and in the brain of others ("Einfühlung").

4. The ability to abandon the egocentric perspective in order to adopt an allocentric perspective, inhibiting the emotional contagion [13].

Fully, Berthoz hypothesis is that these processes require the contribution (albeit not exclusive) of different brain mechanisms involved in spatial perception, in mental manipulation of the reference systems and in perspective change.

\section{Design Of A Video Game For The}

\section{MeAsurement Of Perspective TAKING SKILls}

The goal of this project is the design and the development of a video game aimed at measurement of the player's perspective taking skills.

We think that the videogame tool is particularly suitable for the creation of an instrument for measuring perspective taking skills, for two main reasons.
First, the physics engine present in development environments, and the sophisticated cameras management systems, allow to get absolutely realistic "points of view" [16].

Secondly, the game allows an advantage in terms of motivation, and offers the ability to create, according to the cited work of Hughes, tasks that make sense to the child.

The space of the game is not a new subject in the scientific literature [17]. According to Thon, "since many computer games are set in complex fictional worlds, one has to distinguish between the space of the fictional world as a whole and the spaces that the player can interact with through the interface. Jesper Juul draws a similar distinction between world space and game space. Since most of the events in computer games take place in the game space, it seems to be mainly this part of the space of the fictional world that is of interest with regard to the question of spatial perspective in computer games"'[18, 19].

Furthermore, the game space is mainly an experiential space:

"When gamer magazines want to describe the experience of gameplay, they are more likely to reproduce maps of the game world than to recount their narratives. As I have noted elsewhere, these maps take a distinctive form not objective or abstract top-down views but composites of screenshots which represent the game world as we will encounter it in our travels through its space. Game space never exists in abstract, but always experientially" [20].

The theoretical framework of this work is made by the spatial theory of empathy.

The hypothesis that studies of this nature are applicable to the digital environment is experimentally established by Berthoz:

"We designed a behavioral study in which participants interacted spontaneously with a life-sized virtual tightrope walker walking forward, backward and leaning to her left or right on a rope. Here, we report results showing that participants automatically embodied the avatar's leaning movements [...]'[13].

The idea of creating a video game on perspective taking has reported immediately to mind the "three mountains problem» and the subsequent scientific debate about the age at which the child acquires the skill of perspective taking.

The game prototype requires the user to navigate in three-dimensional space through an avatar.

The player's default view is a semi-subjective view, with the avatar seen from behind.

In this work, we followed the categorization proposed by Britta Neitzel [21], which, taking up the work of Jean Mitry on The Aesthetics and Psychology of the Cinema [22], distinguishes between subjective, semi subjective or objective points of view.

According to this categorization, a point of view is subjective when the position from which the game space is presented coincides with the position of the avatar (Fig. 4).

The semi-subjective perspective is given when the point of view is related to the movements of the avatar.

In the words of Neitzel: "Point of view is connected to the movements of the avatar; it is not a substitute for the 
viewpoint as in case of the subjective POV, but rather a viewing-with" [21].

Thon points out that "although the spatial position of the avatar is not the same as that of the camera, the camera's position is always linked to the avatar" [18] (Fig. 5).

Finally, when the view is not related to the position and movement of the avatar, you can talk about objective point of view.

"The objective point of view shows a game space from a position that is not part of this game space (as is the case with a subjective point of view) and is not connected to an entity in the game space (as is the case with a semisubjective point of view)" [18] (Fig. 6).

The player addresses three different tasks of increasing difficulty.

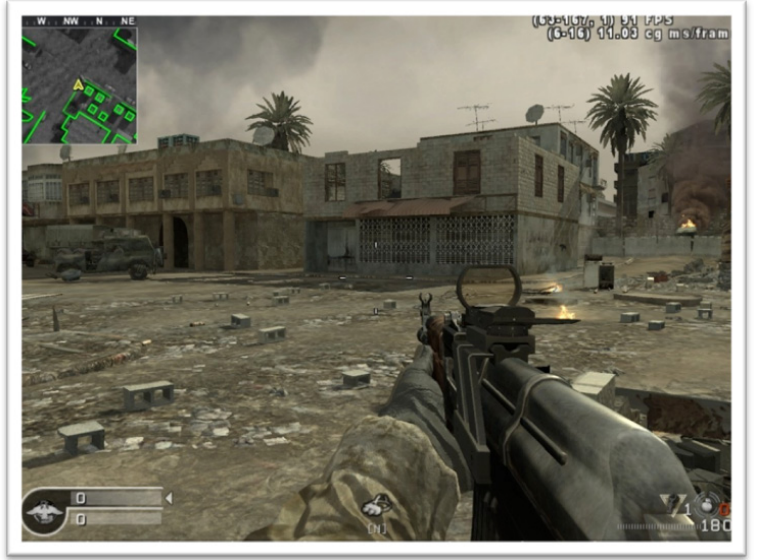

Figure 4. Subjective point of view in Call of Duty.

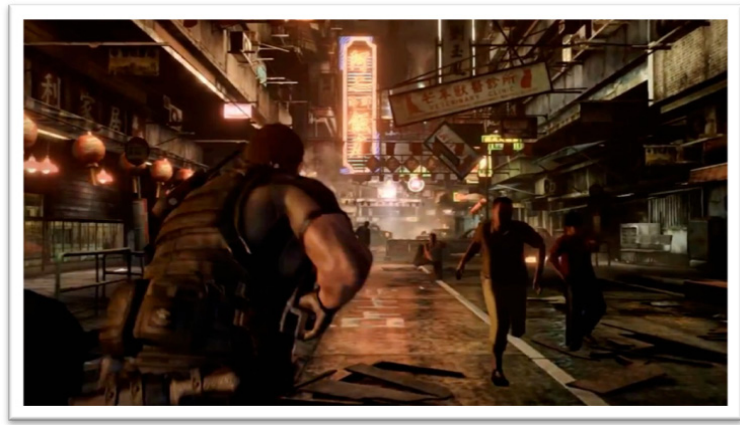

Figure 5. Semi - subjective point of view in Resident Evil 6. Camera follows avatar.

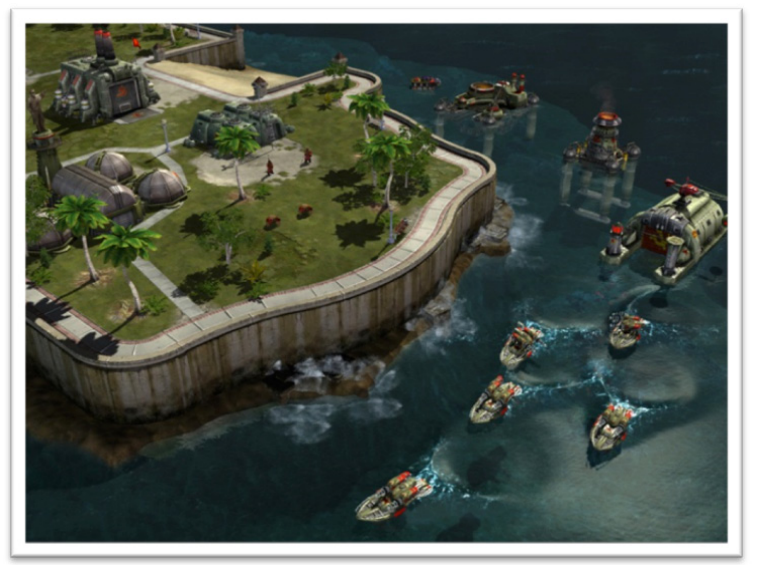

Figure 6. - objective point of view in Command\&Conquer Red Alert
The first two tasks are complementary and have the purpose of measuring the perspective taking skills, the third task has the objective of measuring mental rotation skills.

\section{A. First Task}

In the first task, the player's avatar is in a park, and has in front of him two men. A window shows the point of view of one of these two men. The player's task is to click on the man whose point of view is shown in the top window (Fig. 7-10).

The player can select different points of view by pressing a key on the keyboard, switching from semi subjective to subjective view, and from subjective to topdown (objective) view (Fig. 11+12).

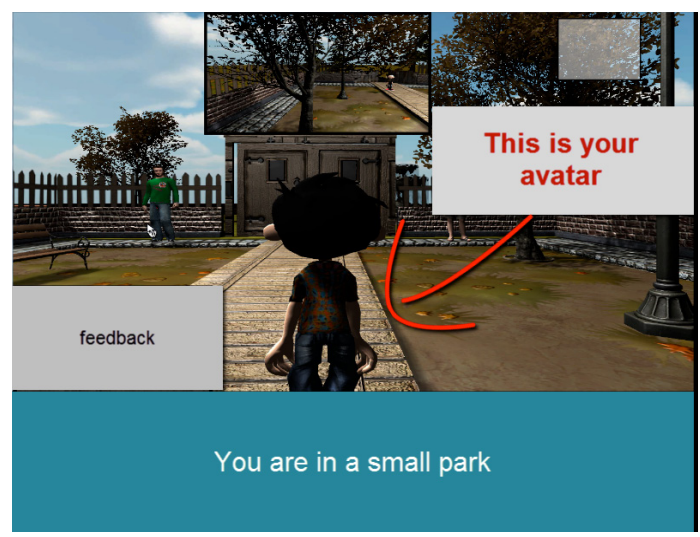

Figure 7. Tutorial snapshot - Task 1

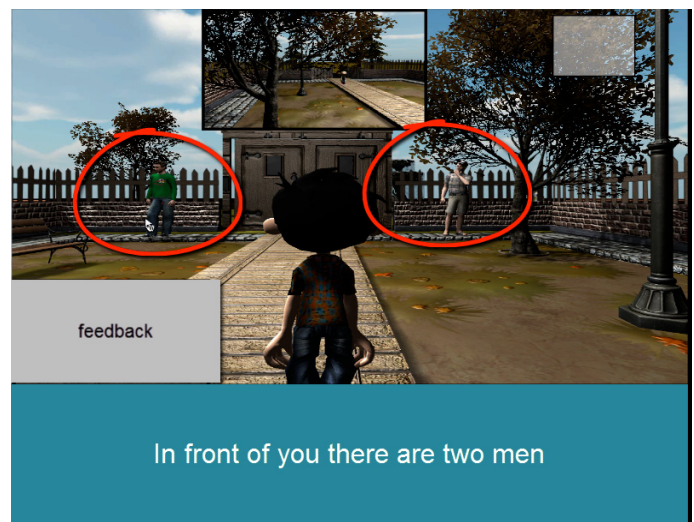

Figure 8. Tutorial snapshot - Task 1

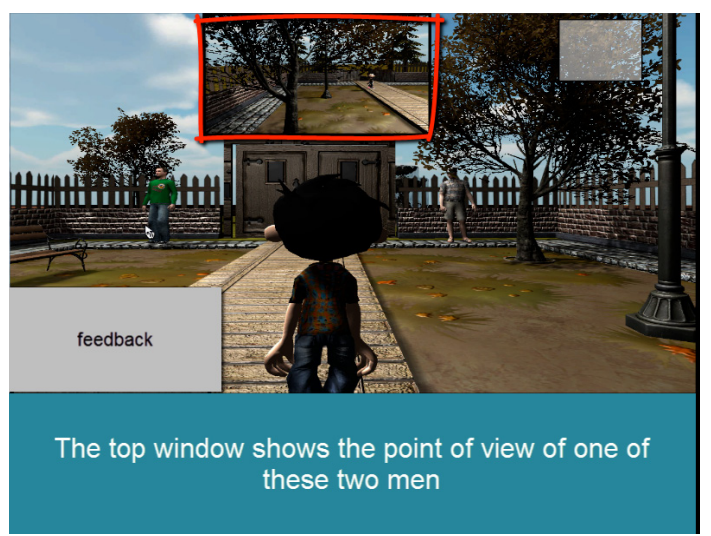

Figure 9. Tutorial snapshot - Task 1 
Perception Of Space, Empathy And Cognitive Processes: Design Of A Video Game For The Measurement...

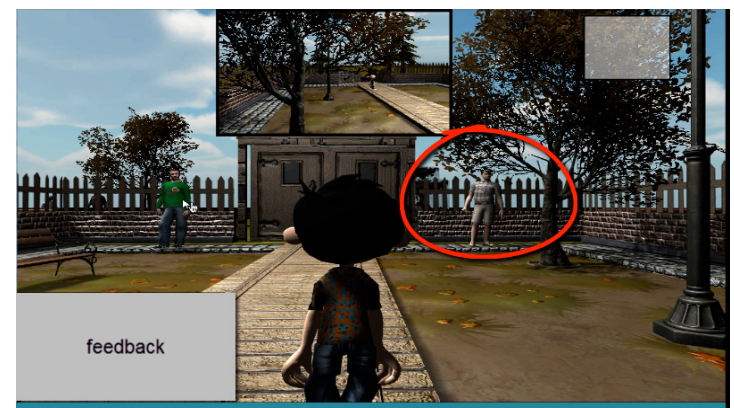

Click on the man to whom, according to you, the viewpoint in the top window belongs to

Figure 10. Tutorial snapshot - Task 1

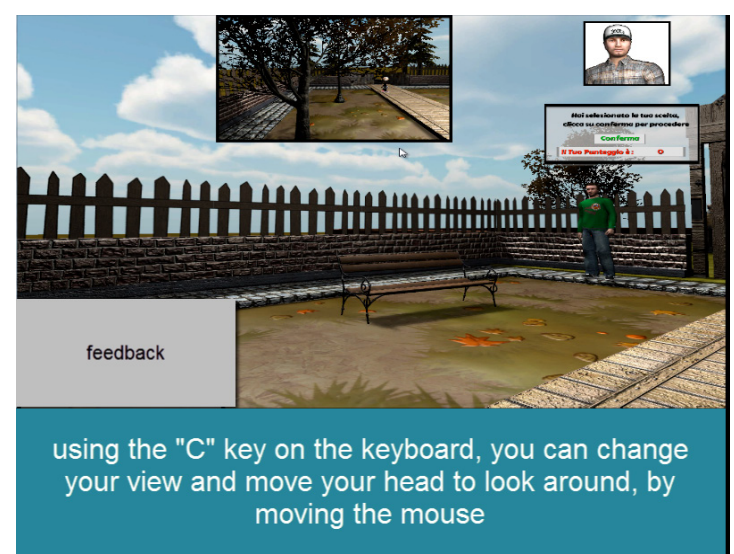

Figure 11. Tutorial snapshot - Task 1

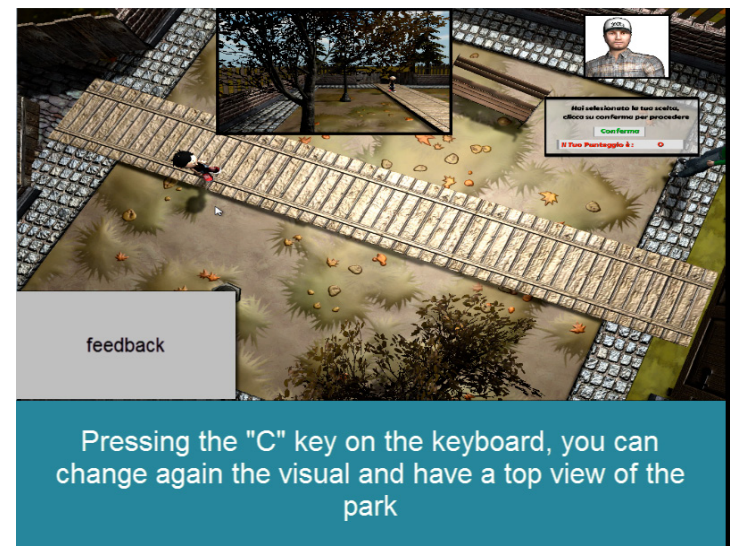

Figure 12. Tutorial snapshot - Task 1

To access the next task, the player must provide five consecutive correct answers.

\section{B. Second Task}

In the second task, the player has in front him of only one man. Two windows in the upper screen show two point of view, the point of view of the man in the park, and a fake point of view. The player's task is to click on the window showing the point of view of the man in the park (Fig. 13-16).

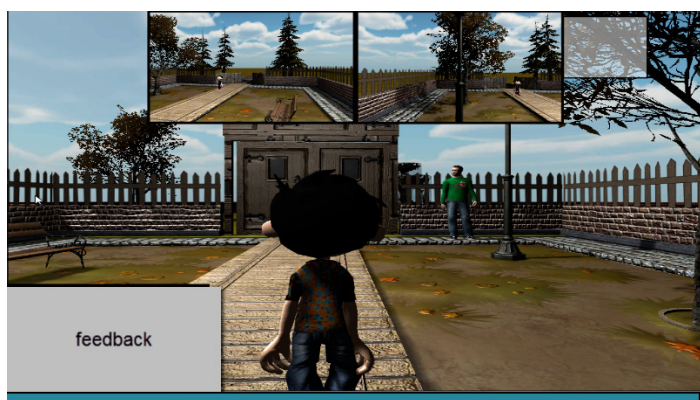

In the second level, your task is slightly different

Figure 13. Tutorial snapshot - Task 2

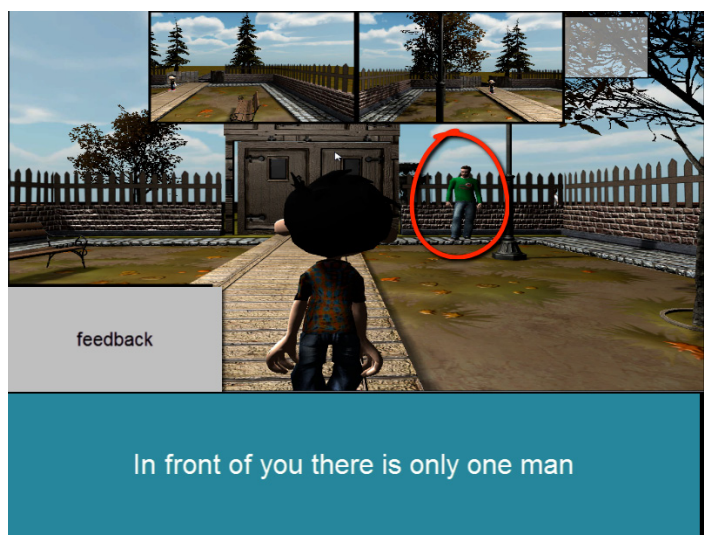

Figure 14. Tutorial snapshot - Task 2

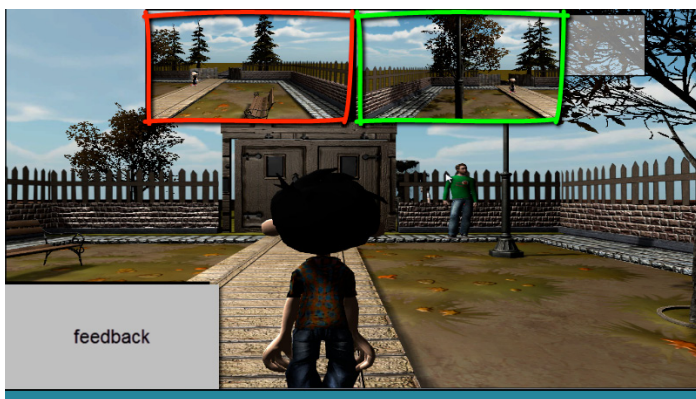

in the top of the screen you have two windows

Figure 15. Tutorial snapshot - Task 2

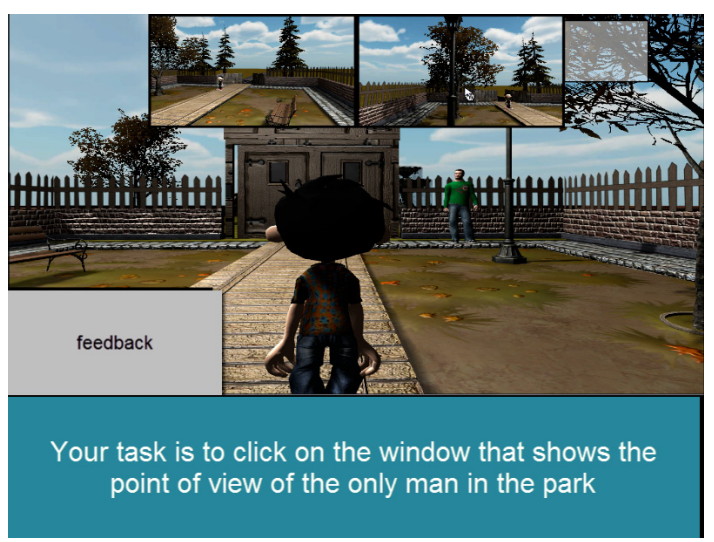

Figure 16. Tutorial snapshot - Task 2 


\section{Third Task}

In the third task, the user is struggling with an invisible man. The player cannot see the man in the park, but can see, in the top window, what the man in the park is seeing. The area of the park has been divided into six zones. By moving the mouse, the user can select the area of the park in which he believes to be the man whose perspective is shown in the top window (Fig. 17-19).

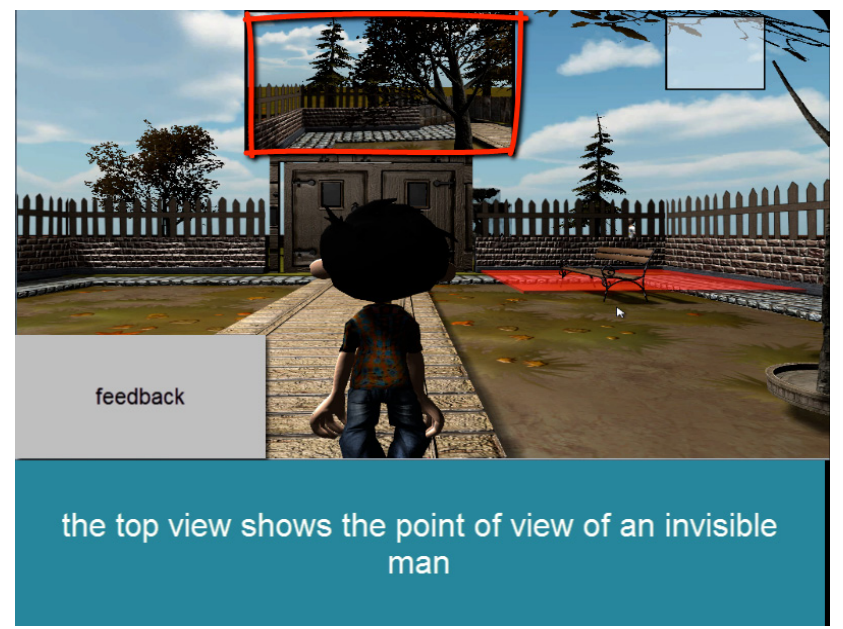

Figure 17. Tutorial snapshot - Task 2

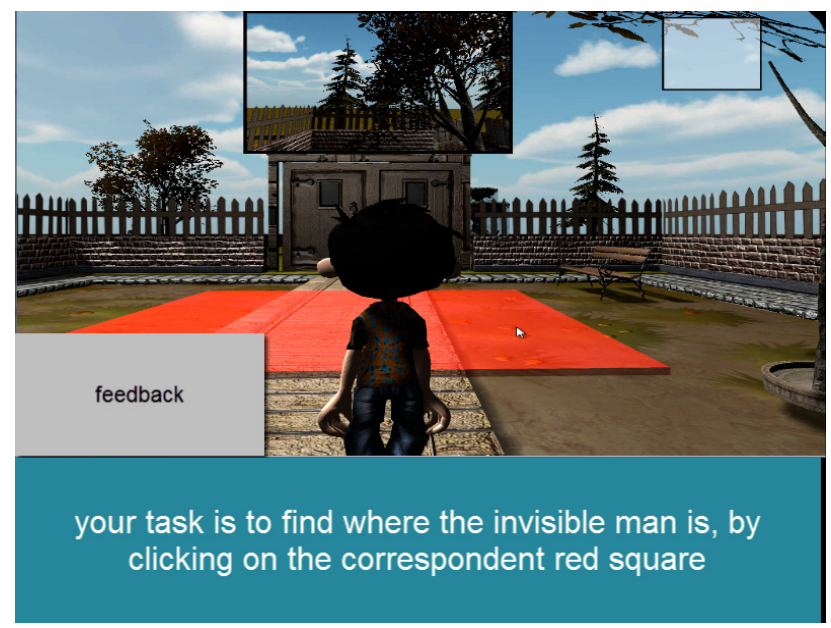

Figure 18. Tutorial snapshot - Task 2

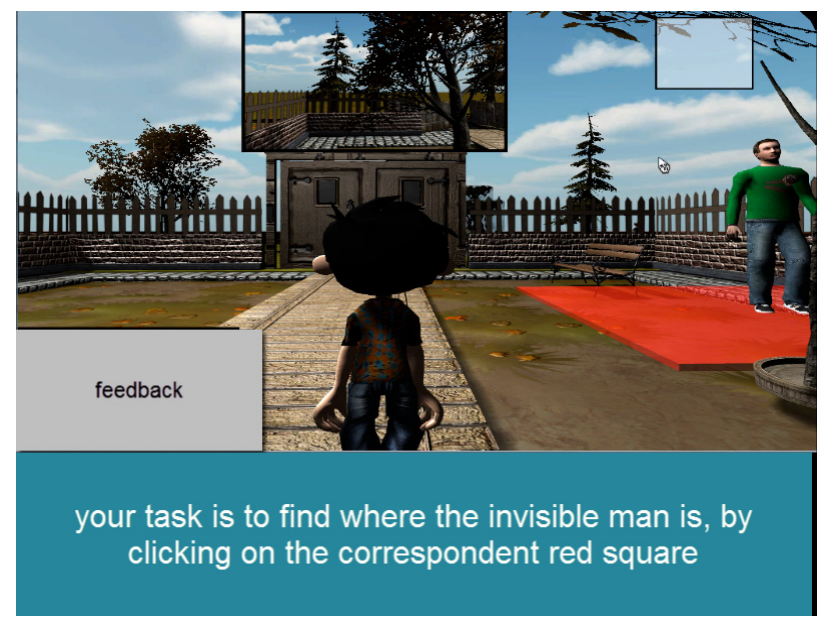

Figure 19. Tutorial snapshot - Task 2 - Feedback

\section{FIRST OBSERVATIONS}

The project has not yet reached a stable version. No data collection was carried out so far. However, the game has been tested in schools, in order to verify the functionality. The comments below have not then the nature of scientific results, but were regarded as contributing to the development of software

The first observations on the behavior of the players showed very different behaviors, which can probably be attributed to gender differences and to the different cognitive strategies.

The substantial differences found are:

- The management of the avatar: of the four subjects, two move the avatar in proximity of the other character, observe the changes in the boxes that show the perspective of the character, show the avatar to the position it occupied at the beginning of the task (marked with screen instructions and with the change of the interface), and only after this phase of exploration provide the answer. Two others, however, does not actually move the avatar from the initial position, observing the scene and provide the answer.

- The management of cameras: of the four subjects, two use the default view and two switch between different cameras, one passing from the semisubjective to subjective perspective, another going from subjective to objective view (top down view).

\section{CONCLUSIONS}

As already mentioned, the aim of the study was the production of an instrument capable of measuring the skill of perspective taking. The current phase of the project has produced a game, currently in alpha testing. Passed the stage of alpha testing, the game will be tested in schools in an attempt to demonstrate reliability and validity, by comparing the results of the game with the results of a battery of tests administered at the same time, such as it is considered necessary to mention the VMI Visual Motor Integration test [23], the scales for the assessment of mental imagery [24], and the IRI (Interpersonal Reactivity Index) PT (perspective taking subscale) [25].

At present, the project has defined the theoretical framework and selected tools for design and development. Specifically, the engine, made in Unity $3 D$, seems to be suitable for the realization of the videogame. The current stage is, on the one hand, to identify with precision the type of task to be submitted to the players and the skills involved in the task, and secondly, to identify methodologies and tools to reduce all the "noise" potentially intervening in measurement process.

\section{REFERENCES}

[1] A. Berthoz, Simplexity: Simplifying Principles for a Complex World: Yale University Press, 2012. http://dx.doi.org/10.12987/ yale/9780300169348.001.0001

[2] F. De Vignemont, and T. Singer, "The empathic brain: how, when and why?," Trends in cognitive sciences, vol. 10, no. 10, pp. 435441, 2006. http://dx.doi.org/10.1016/j.tics.2006.08.008

[3] F. Gaunet, and A. Berthoz, "Mental rotation for spatial environment recognition," Cognitive brain research, vol. 9, no. 1, pp. 91102, 2000. http://dx.doi.org/10.1016/S0926-6410(99)00038-5

[4] J. Piaget, and B. Inhelder, "La représentation de l'espace chez l'enfant," 1948. 
[5] J. Perner, Understanding the representational mind: The MIT Press, 1991

[6] P. Rochat, "Perceived reachability for self and for others by 3-to 5-year-old children and adults," Journal of Experimental Child Psychology, vol. 59, no. 2, pp. 317-333, 1995. http://dx.doi.org/10.1006/jecp.1995.1014

[7] M. Hughes, and M. Donaldson, "The use of hiding games for studying the coordination of viewpoints," Educational Review, vol. 31, no. 2, pp. 133-140, 1979. http://dx.doi.org/10.1080/ 0013191790310207

[8] H. Borke, "Piaget's mountains revisited: Changes in the egocentric landscape," Developmental Psychology, vol. 11, no. 2, pp. 240, 1975. http://dx.doi.org/10.1037/h0076459

[9] U. Frith, and F. De Vignemont, "Egocentrism, allocentrism, and Asperger syndrome," Consciousness and cognition, vol. 14, no. 4, pp. 719-738, 2005. http://dx.doi.org/10.1016/j.concog.2005.04.006

[10] K. Vogeley, and G. R. Fink, "Neural correlates of the first-personperspective," Trends in cognitive sciences, vol. 7, no. 1, pp. 38-42, 2003. http://dx.doi.org/10.1016/S1364-6613(02)00003-7

[11] A. Berthoz, La semplessità: Codice, 2011.

[12] A. Berthoz, "Physiologie du changement de point de vue," L'empathie, pp. 251-275, 2004.

[13] A. Berthoz, and B. Thirioux, "A Spatial and Perspective Change Theory of the Difference Between Sympathy and Empathy," $\mathrm{Pa}$ ragrana, vol. 19, no. 1, pp. 32-61, 2010.

[14] R. Vischer, "Über das optische Formgefühl (1872); Der ästhetische Akt und die reine Form (1874): Über ästhetische Naturbetrachtung (1890)," Drei Schriften zum ästhetischen FormproblemLeipzig, 1927.

[15] E. Husserl, Zur Phänomenologie der Intersubjektivität: Texte aus dem Nachlaß. Zweiter: Springer, 1973. http://dx.doi.org/10.1007/ 978-94-010-2474-7

[16] G. R. Mangione et al., "Measuring Empathy to Support Learning Design and Narrative Game: A Phenomenological Approach." pp. 401-406.

[17] P. A. Di Tore, and G. Raiola, "Exergame-Design and Motor Activities Teaching: An Overview of Scientific Paradigms on Motor Control," Mediterranean Journal of Social Sciences, vol. 3, no. 11, pp. 119-122, 2012.

[18] J.-N. Thon, "Perspective in Contemporary Computer Games," Point of view, Perspective, and Focalization: Modeling Mediation in Narrative, pp. 279-300, 2009.
[19] J. Juul, "Half-real: Video games between real rules and fictional worlds," 2005.

[20] H. Jenkins, "Transmedia storytelling 101," Confessions of an Aca/Fan: The Official Weblog of Henry Jenkins, 2007.

[21] B. Neitzel, "Point of View and Point of Action. A Perspective on Perspective in Computer Games."

[22] J. Mitry, and C. King, The Aesthetics and Psychology of the Cinema: Indiana University Press, 1997.

[23] K. E. Beery, "The Beery-Buktenica Developmental Test of Visual-Motor Integration, (Beery VMI-5)," Minneapolis: NCS Pearson, 2004.

[24] S. J. McKelvie, "The VVIQ as a psychometric test of individual differences in visual imagery vividness: A critical quantitative review and plea for direction," Journal of Mental Imagery, 1995.

[25] M. H. Davis, "A multidimensional approach to individual differences in empathy," 1980.

\section{AUTHORS}

Pio Alfredo Di Tore is PhD student in "Methodology of Educational Research", Department of Human Sciences, Philosophy and Education, University of Salerno. Among the most recent works:

Di Tore, P. A., Carlomagno, N., Di Tore, S., \& Sibilio, M. (2013). Digital Umwelt: Towards a Didactic Use of Natural Interfaces. International Journal of Digital Literacy and Digital Competence (IJDLDC), 4(1)

Di Tore P (2012). Body, Movement, Learning And Technology: A "Simplex" History. In: Carlomagno N. Corporeity And Technologies For Education In The Italian School: Historical Contexts And Educational Dimensions. SZOMBATHELY:Savaria University Press

This article is an extended and modified version of a paper presented at the Third International Workshop on Adaptive Learning via Interactive, Collaborative and Emotional approaches (ALICE 2013), held on July 35,2013 , in Taichung, Taiwan, in conjunction with the 7th International Conference on Complex, Intelligent and Software Intensive Systems (CISIS 2013).Manuscript received 30 November 2011. Published as submitted by the author(s). 